\title{
Correction to: Proposed Model for Radio Wave Attenuation due to Rain (RWAR)
}

\author{
Hitesh Singh $^{1} \cdot$ Vivek Kumar $^{1}$ (D) $\cdot$ Kumud Saxena $^{1} \cdot$ Bonev Boncho $^{2} \cdot$ Ramjee Prasad $^{3}$ \\ Published online: 15 March 2021 \\ (c) Springer Science+Business Media, LLC, part of Springer Nature 2021
}

\section{Correction to: Wireless Personal Communications (2020) 115:791-807 https://doi.org/10.1007/s11277-020-07598-3}

There was a typing error in the fourth author's name in the initial online publication. The original article has been corrected.

Publisher's Note Springer Nature remains neutral with regard to jurisdictional claims in published maps and institutional affiliations.

The original article can be found online at https://doi.org/10.1007/s11277-020-07598-3.

Vivek Kumar

vivek.bansal1977@gmail.com

Hitesh Singh

hitesh.singh85@gmail.com

Kumud Saxena

saxenakumud@gmail.com

Bonev Boncho

bbonev@tu-sofia.bg

Ramjee Prasad

ramjee@btech.au.dk

1 Noida Institute of Engineering and Technology, Greater Noida, India

2 Technical University of Sofia, Sofia, Bulgaria

3 Aarhus University, Herning Campus, Herning, Denmark 